\title{
Renal Oncocytoma: Clinical and Therapeutic Aspects about a Case Series and Literature Review
}

\author{
Yoro Diallo 1* $^{*}$ Racine Kane ${ }^{2}$, Saint Charles N. Kouka1, Aliou Amadou Dia1, \\ Cyrille Ze Ondo ${ }^{3}$, Abdoulaye N'diaye ${ }^{2}$, Adamson Phiri ${ }^{1}$, Eden Kwamé Dagadou ${ }^{1}$, \\ Mamadou Ba ${ }^{3}$, Cheickna Sylla ${ }^{1}$ \\ ${ }^{1}$ Department of Urology, Faculty of Health Sciences, University of Thies, Thies, Senegal \\ ${ }^{2}$ Department of Urology, Principal Hospital of Dakar, Dakar, Senegal \\ ${ }^{3}$ Department of Urology-Andrology Teaching Hospital Aristide Le Dantec of Dakar, Dakar, Senegal \\ Email: ${ }^{*}$ yorodiallo@hotmail.com
}

Received 23 March 2015; accepted 16 May 2015; published 19 May 2015

Copyright (C) 2015 by authors and Scientific Research Publishing Inc.

This work is licensed under the Creative Commons Attribution International License (CC BY).

http://creativecommons.org/licenses/by/4.0/

(c) (i) Open Access

\begin{abstract}
Introduction: The gold of this work was to study the clinical and therapeutic management aspects of renal oncocytoma in our settings. Our Observations: Case 1: there was a 44-year-old patient being followed up for a urinary tract infection due to Escherichia coli. The urological CT-scan showed a tumor-like process on a horseshoe kidney. Radical nephrectomy was performed and the histology report confirmed renal oncocytoma; Case 2: it involved a 62-year-old hypertensive patient. Clinical examination revealed a grade II cystocele and medical imaging showed a tumor-like mass at the lower pole of the right kidney. Radical nephrectomy was performed and histology was concluded in favor of renal oncocytoma; Case 3: there was a 64-year-old patient monitored for chronic renal failure and on dialysis for 6 months. Imaging showed a heterogeneous mass developing from the kidney. Histology and immunohistochemistry confirmed renal oncocytoma. Conclusion: Imaging could contribute greatly to preoperative diagnosis. However, there is a need to think about renal oncocytoma when evaluating kidney tissue masses.
\end{abstract}

\section{Keywords}

Renal Oncocytoma, Benign Tumor, Imaging, Nephrectomy

\footnotetext{
"Corresponding author.
}

How to cite this paper: Diallo, Y., Kane, R., Kouka, S.C.N., Dia, A.A., Ondo, C.Z., N'diaye, A., Phiri, A., Dagadou, E.K., Ba, M. and Sylla, C. (2015) Renal Oncocytoma: Clinical and Therapeutic Aspects about a Case Series and Literature Review. Open Journal of Urology, 5, 65-69. http://dx.doi.org/10.4236/oju.2015.55010 


\section{Introduction}

Renal oncocytoma is a rare benign tumor that is part of a heterogeneous group of large epithelial cell tumors [1]. Its diagnosis is often incidental, discovered during an imaging examination or on post-operative pathological investigations [2]. The appearance on CT scan or MRI is usually that of a tissue mass with a "central fibrous scar stellar"; however there are many atypical cases at imaging. Indeed, as the histological diagnosis is not established, it is difficult to distinguish renal oncocytoma from other oncolytic types of malignant tumors which are renal adenocarcinoma and eosinophilic cell chromophobe carcinoma [2]. We present 3 clinical case reports of renal oncocytoma, and highlight the clinical, imaging and therapeutic aspects.

\section{Our Observations}

\section{CASE 1:}

The first case is a patient of 44 years old, with no particular medical history, received for a right lumbar pain evolving for seven months with moderate intensity, without voiding disorders. On physical examination, he had a good general status; however, the urine was smelly. The right lumbar fossa was slightly sensitive.

Ultrasonography of the urinary tract noticed a tissue malignancy tumor at the lower pole of the right kidney and intravenous urography objectified tumor syndrome developed on the right kidney with stretching of the lower caliceal group.

The uroscan mentioned a rounded tumoral process of $4 \mathrm{~cm}$ diameter occurring on a horseshoe kidney (Figure 1).

This tumor was the seat of a hypodense central beach and showed, after contrast injection, the same dynamic of enhancement that adjacent normal renal cortex. Laboratory tests showed good kidney function and Urine culture was identified an Escherichia coli infection and the presence of crystals of calcium oxalate and uric acid. Enlarged right section of the horseshoe kidney isthmus with nephrectomy was performed (Figure 2). The postoperative follow-up was uneventful.

Histopathological examination found a benign epithelial tumor of the right kidney corresponding to an oncocytoma of $4 \mathrm{~cm}$ diameter, limited by a fibrous capsule and removed entirely. The rest consisted of kidney infarct substantially at foci of the kidney cortex. The renal hilum and the pelvicaliceal system were normal.

CASE 2:

There was a woman of 62 years old, with a history of high blood pressure, under treatment, which complained of a right lumbar pain associated with dysuria, pollakiuria and urgency voiding. Physical examination revealed a large right kidney and cystocele grade II.

Ultrasound highlighted heterogeneous hypoechogenic solid mass of the upper pole of the right kidney of about $6 \mathrm{~cm}$ maximum diameter with moderate vascularization at Doppler color. CT scan concluded of a right

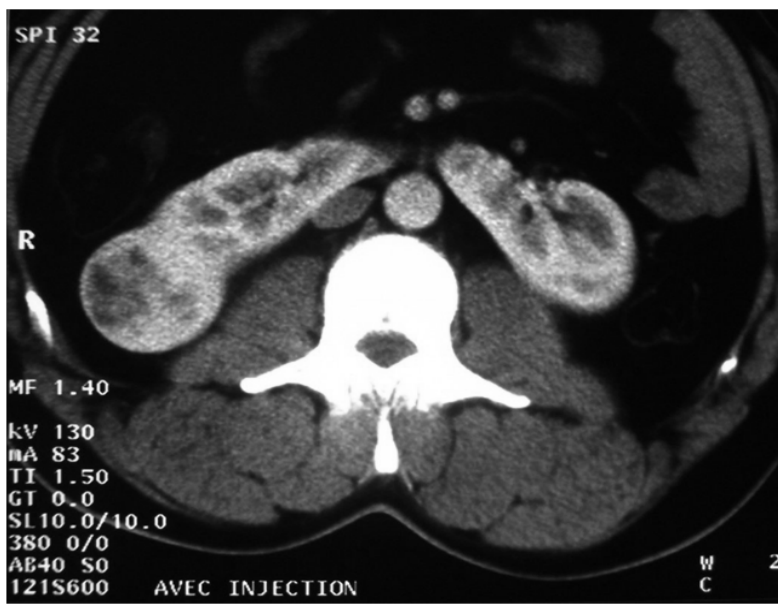

Figure 1. Case 1: CT scan shows a rounded tumoral process of $4 \mathrm{~cm}$ in diameter with a central hypodense beach, occurring on a horseshoe kidney presenting the same dynamic of enhancement that of adjacent normal renal cortex after injection of iodinated contrast. 


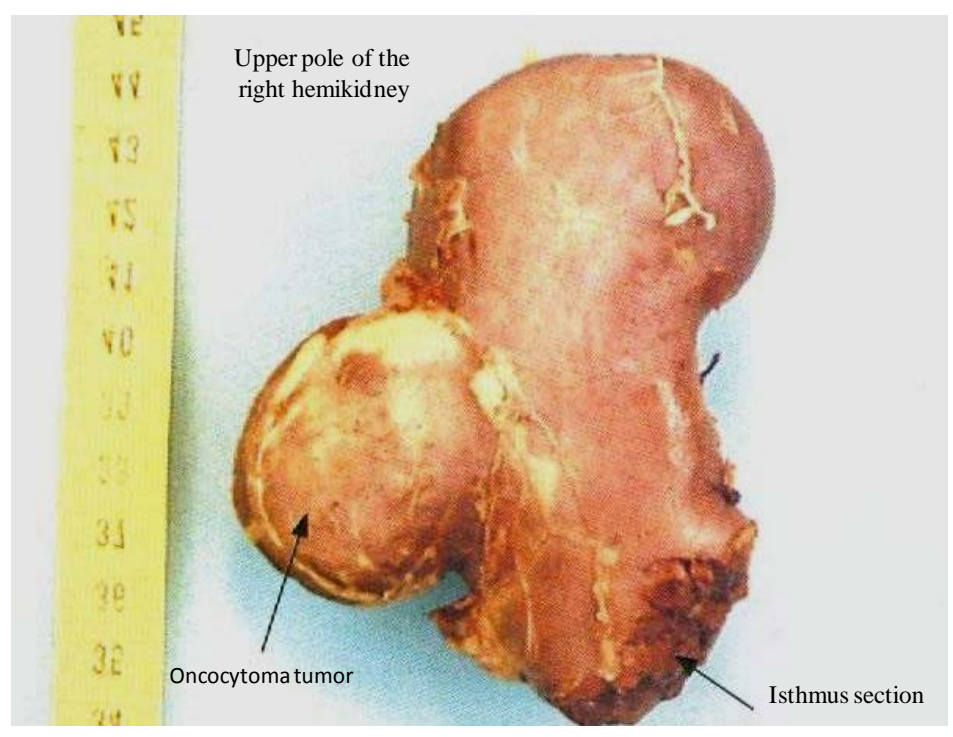

Figure 2. Case 1: macroscopic appearance of the tumor on the oncocytic horseshoe kidney.

renal tumor with heterogeneous density and a central hypodense stellar scar, localized at the posterior portion of the upper pole, whose diameter was $6 \mathrm{~cm}$ (Figure 3). Radical nephrectomy was performed by midline laparotomy. The postoperative course was uneventful. Pathological examination mentioned right kidney weighing 245 grams with its cut surface yellowish tumor chamois measured $6 \times 6 \mathrm{~cm}$, centered by a $2 \mathrm{~cm}$ scar whose histology was in favor of a renal oncocytoma.

CASE 3:

64-year-old patient, followed for chronic renal failure evolving for more than 15 years. The surgical history retained left ureteral stenosis that required ureteral reimplantation.

He complained of a right lumbar pain without associated urinary disorders.

Computed tomography objectified a heterogeneous tumor mass developed at the medial part of the right kidney, of $5 \mathrm{~cm}$ diameter without invasion of the renal sinus and without dilation of renal excretory cavities. Right nephrectomy was performed on the basis of the diagnostic items.

During the follow-up, 6 months of hemodialysis were required because of a renal failure worsening.

At histological examination of the surgical specimen, the immunohistochemical study by indirect immunoperoxidase in three layers on deparaffinized sections confirmed the diagnosis of renal oncocytoma. In addition, there were lesions of chronic interstitial nephropathy.

\section{Discussion}

Renal oncocytoma was described for the first time by Zipple [1] in 1942. It is an infrequent benign tumor representing approximately 3\% to $7 \%$ of solid tumors of the kidney [2]. The oncocytoma is generally observed in adults in the 6th decade of life with a male predominance (sex ratio 2/1) [3].

Our series concerned a relatively young patient (44 years) compared with cases reported in literature [3].

Wang reported an average age of 62 years with extremes from 52 to 77 years [1]. Horseshoe kidney is the most common renal fusion anomaly, its incidence is estimated at $0.25 \%$ of the general population [4]. However, the association between renal oncocytoma and horseshoe kidney is very rare.

Klimbing in 1986 described a renal oncocytoma exceptional case on horseshoe kidney [5]. Although in our study, the oncocytic tumor was developed on the right side in all our patients, both kidneys are equally affected [6].

There are very few clinical or para-clinical symptoms specifics to renal oncocytoma. In our series, the tumor location was unique but there are cases of multiple renal oncocytoma including the Birt-Hogg-Dubé syndrome and oncocytomatosis [7]. The ultrasonographic appearance of renal oncocytoma is usually that as a well-circumscribed solid renal cortical masses, hypoechogenic, fairly homogeneous unencapsulated of exophytic growth with a central stellate scar and a characteristic vascular pattern called "pattern spokewheel". Some renal onco- 


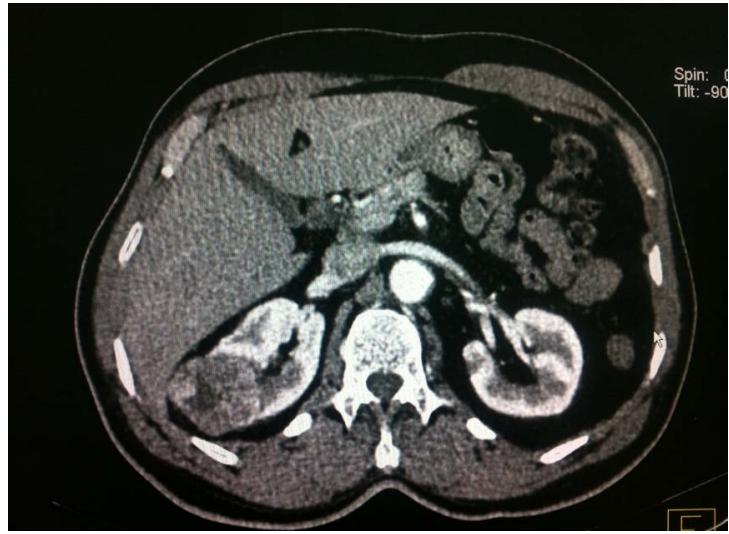

Figure 3. Case 2: CT scan shows typical renal oncocytoma as a right renal tumor with heterogeneous density and a central hypodense stellar scar, localized at the posterior portion of the upper pole, whose diameter was $6 \mathrm{~cm}$.

cytoma are relatively isoechogenic or slightly hyperechogenic compared to adjacent renal parenchyma [8] [9].

The CT urography remains the main radiological examination in the diagnosis of renal tumors. It allows highlighting a hypodense image in a well-demarcated homogeneous tumor. Eiss et al. [10] have described at CT scan, three major groups of non-multiple renal oncocytoma:

- the renal oncocytoma $(>3 \mathrm{~cm})$ seat of the classic "central stellar scar",

- the large renal oncocytoma with or without "stellar central scar", homogeneous or heterogeneous with calcifications,

- and the small oncocytoma $(<3 \mathrm{~cm})$ that have for the differential diagnosis of chromophobe cell carcinoma.

In MRI, there are no additional specific diagnostic criteria relative to the scanner. The signal of the small oncocytoma is typically low relative to the renal parenchyma on T1 and T2-weighted images. This aspect is related to the tumor stromal edema. Identically to that of CT, the contrast enhancement is rapid and uniform. The central radial scar has a low signal on T1 compared to peri-tumor tissue and hyperintense on T2 due to the myxoid component [11]. Although essential to the diagnosis, MRI or scanner may have difficulty in differentiating renal oncocytoma and renal adenocarcinoma with oncocytic form or renal chromophobe carcinoma; this difficulty in differential diagnosis often justify the indication of radical nephrectomy [12]. Rosenkrantz et al. in one of the largest series examining the MRI features of renal oncocytoma and chromophobe renal carcinomas have concluded that there are no specific diagnostic criteria between these two entities [13]. This difficulty led to the consideration that renal oncocytoma is a benign tumor with metastatic capabilities and it was only in the $90 \mathrm{~s}$ that its benign nature was actually established [3]. In general, it is histologiy which rectifies the renal oncocytoma diagnosis. Its appearance is characteristic with a buff beige pink hue or homogeneous mahogany Brown, made of large epithelial cells arranged in well-defined limits.

The size of the tumor is variable. In our study, it measured between 4 and $6 \mathrm{~cm}$ on its major axis. Alamara reported an average of $3.2 \mathrm{~cm}$ with extremes of 0.6 to $14 \mathrm{~cm}$ [14]. Immunohistochemistry can differentiate renal cell carcinoma and renal oncocytoma and other renal tumors by studying the anti-cytokeratin 7 and anticytokératine 8 [15]. Conservative treatment is recommended and monitoring in asymptomatic cases must be the rule [10]. However, in view of the diagnostic difficulties that arise with malignant tumors, the need for renal biopsy is important. Expanded nephrectomy is performed in most of the cases. Fan [16] reported $76.9 \%$ of cases. In our study, three patients underwent radical nephrectomy and the diagnosis of oncocytoma was retained and maintained only by histological examination of the post operation specimen. Nowadays, we observe, more and more the advent of conservative treatment of renal oncocytoma as cryoablation or radiofrequency ablation with interventional radiology. Senegal and many other African countries do not yet have these new therapeutic modalities, so, radical nephrectomy and monitoring of asymptomatic cases remain the rule.

\section{Conclusion}

The renal oncocytoma is a rare benign epithelial tumor in which the diagnosis should be considered in front of 
any imaging process renal tissue with "stellar central scar”. However, given the similarity and diagnosis difficulties with some renal cancers such as chromophobe renal cell carcinoma, caution should be in order and verification by histological biopsy should be mandatory.

\section{Competing Interests}

The authors declare that they have no competing interests.

\section{References}

[1] Wang, L.H., Wang, Z.X. and Sun, Y.H. (2008) Preoperative Diagnosis of Renal Oncocytoma: Case Report and Literature Review. Journal of Medical Colleges PLA, 23, 308-312. http://dx.doi.org/10.1016/S1000-1948(08)60058-1

[2] Lieber, M.M. (1993) Renal Oncocytoma. Urologic Clinics of North America, 20, 355-359.

[3] Marciano, S., Petit, P., Lechevallier, E., et al. (2001) Renal Onococytic Adenoma. Journal of Radiology, 82, 455-461.

[4] Jira, H., Ameur, A., Kasmaoui, E., et al. (2002) Rein en fer à cheval pathologique. À propos de 13 cas. Annales d'Urologie, 36, 22-25. http://dx.doi.org/10.1016/S0003-4401(01)00067-5

[5] Klimbing, I., Epstein, H. and Wajsman, Z. (1986) Oncocytoma in a Horseshoe Kidney. Journal of Urology, 135, 1002.

[6] Hajri, M., Moualli, S.B. and Gelloub, H. (2001) L'oncocytome du rein. À propos de sept cas. Annales d'Urologie, 35, 139-144. http://dx.doi.org/10.1016/S0003-4401(01)00015-8

[7] Pavlovich, C.P., Walther, M.M., Eyler, R.A., Hewitt, S.M., Zbar, B., Linehan, W.M., et al. (2002) Renal Tumors in the Birt Hogg-Dubé Syndrome. The American Journal of Surgical Pathology, 26, 1542-1552. http://dx.doi.org/10.1097/00000478-200212000-00002

[8] Lou, L., Teng, J., Lin, X. and Zhang, H. (2014) Ultrasonographic Features of Renal Oncocytoma with Histopathologic Correlation. Journal of Clinical Ultrasound, 42, 129-133. http://dx.doi.org/10.1002/jcu.22128

[9] Glaudon, M., Lefevre, F., Martin, B.A., et al. (1998) Produit de contraste et exploration échographique du rein et de ses vaisseaux. Masson, Paris.

[10] Eiss, D., Larousserie, F., Mejean, A., Ghouadni, M., Merran, S., Correas, J.M. and Hélénon, O. (2005) Adénome oncocytaire du rein: Redéfinition des critères diagnostiques en tomodensitométrie. Journal of Radiology, 86, 17731782. http://dx.doi.org/10.1016/S0221-0363(05)81521-5

[11] Roy, C., Jeantroux, J., Tétékpor, S. and Lindner, V. (2006) Tumeurs du Rein. Journal de Radiologie, 87, $1025-1054$. http://dx.doi.org/10.1016/S0221-0363(06)74126-9

[12] Heidenreich, A. and Ravery, V. (2004) Preoperative Imaging in Renal Cell Cancer. World Journal of Urology, 22, 307-315. http://dx.doi.org/10.1007/s00345-004-0411-2

[13] Rosenkrantz, A.B., Hindman, N., Fitzgerald, E.F., Niver, B.E., Melamed, J. and Babb, J.S. (2010) MRI Features of Renal Oncocytoma and Chromophobe Renal Cell Carcinoma. AJR American Journal of Roentgenology, 195, W421W427. http://dx.doi.org/10.2214/AJR.10.4718

[14] Karapanagiotou, E.M., Tourkantonis, I., Xyla, V., et al. (2008) Renal Oncocytoma: A Case Report and Short Review of the Literature. European Journal of Internal Medicine, 19, e67-e69. http://dx.doi.org/10.1016/j.ejim.2008.03.003

[15] Osunkoya, A.O., Cohen, C., Lawson, D., et al. (2009) Claudin-7 and Claudin-8: Immunohistochemical Markers for the Differential Diagnosis of Chromophobe Renal Cell Carcinoma and Renal Oncocytoma. Human Pathology, 40, $206-210$. http://dx.doi.org/10.1016/j.humpath.2008.07.002

[16] Fan, Y.-H., Chang, Y.-H., Huang, W.J.S., Chung, H.-J. and Chen, K.-K. (2008) Renal Oncocytoma: Clinical Experience of Taipei Veterans General Hospital. Journal of the Chinese Medical Association, 71, 254-258. http://dx.doi.org/10.1016/S1726-4901(08)70116-3 